\title{
Chlorination of a Zeolitic-Imidazolate Framework Tunes Packing and van der Waals Interaction of Carbon Dioxide for Optimized Adsorptive Separation
}

Lik H. Wee,* Steven Vandenbrande, Sven M. J. Rogge, Jelle Wieme, Karel Asselman, Erika O. Jardim, Joaquin Silvestre-Albero, Jorge A. R. Navarro, Veronique Van Speybroeck, Johan A. Martens, and Christine E. A. Kirschhock*

Cite This: J. Am. Chem. Soc. 2021, 143, 4962-4968

Read Online

ABSTRACT: Molecular separation of carbon dioxide $\left(\mathrm{CO}_{2}\right)$ and methane $\left(\mathrm{CH}_{4}\right)$ is of growing interest for biogas upgrading, carbon capture and utilization, methane synthesis and for purification of natural gas. Here, we report a new zeolitic-imidazolate framework (ZIF), coined COK-17, with exceptionally high affinity for the adsorption of $\mathrm{CO}_{2}$ by London dispersion forces, mediated by chlorine substituents of the imidazolate linkers. COK-17 is a new type of flexible zeolitic-imidazolate framework $\mathrm{Zn}$ (4,5-dichloroimidazolate $)_{2}$ with the SOD framework topology. Below $200 \mathrm{~K}$ it displays a metastable closed-pore phase next to its stable open-pore phase. At temperatures above $200 \mathrm{~K}$, COK-17 always adopts its open-pore structure, providing unique adsorption sites for selective

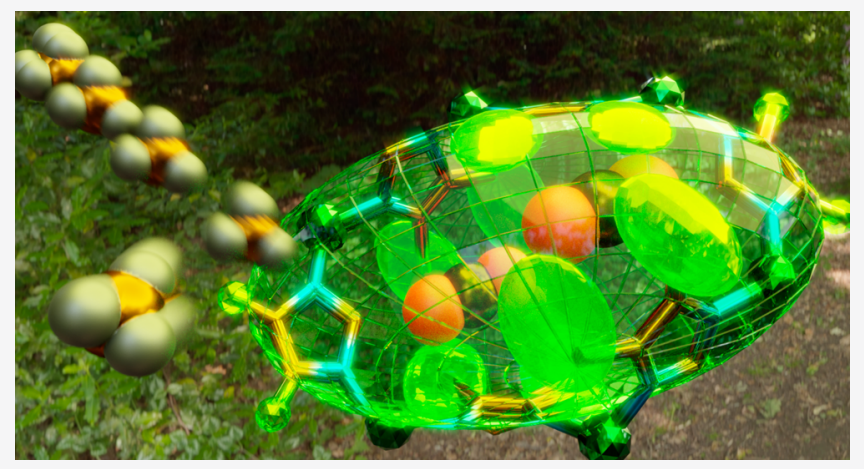
$\mathrm{CO}_{2}$ adsorption and packing through van der Waals interactions with the chlorine groups, lining the walls of the micropores. Localization of the adsorbed $\mathrm{CO}_{2}$ molecules by Rietveld refinement of $\mathrm{X}$-ray diffraction data and periodic density functional theory calculations revealed the presence and nature of different adsorption sites. In agreement with experimental data, grand canonical Monte Carlo simulations of adsorption isotherms of $\mathrm{CO}_{2}$ and $\mathrm{CH}_{4}$ in COK-17 confirmed the role of the chlorine functions of the linkers and demonstrated the superiority of COK-17 compared to other adsorbents such as ZIF-8 and ZIF-71.

\section{INTRODUCTION}

Adsorption of carbon dioxide on a porous material for its separation from methane in $\mathrm{CO}_{2} / \mathrm{CH}_{4}$ gas mixtures is a green key technology compared to conventional amine scrubbing. For renewable fuel production, ${ }^{1} \mathrm{CO}_{2} / \mathrm{CH}_{4}$ separation is an essential step for upgrading biogas and sustainable methane production from carbon dioxide via carbon capture and utilization (CCU) strategies. ${ }^{2,3}$ Metal-organic frameworks (MOFs) composed of metal ions/clusters and organic linkers are particularly useful for designing selective adsorbents for CCU because of their exceptional host-guest interactions. ${ }^{4,5}$ Especially, tuning of the chemical functionality of the linker can enhance the interaction with $\mathrm{CO}_{2}{ }^{6}$ Furthermore, MOFs can easily be structured into macroscopic bodies ${ }^{7}$ or dispersed into membranes, ${ }^{8,9}$ desirable for use in direct separation in traditional PSA or TSA operations, ${ }^{10}$ or as MOF-based membranes. ${ }^{11-18}$

Zeolitic-imidazolate frameworks (ZIFs), a subfamily of MOFs, consist of tetrahedrally coordinated transition-metal cations, mostly $\mathrm{Zn}^{2+}$ or $\mathrm{Co}^{2+}$, bridged by imidazolates and display zeolite-like topologies (e.g., SOD, LTA, and RHO zeolite structure types). ${ }^{19,20}$ They have attracted considerable attention as molecular sieves for gas separation because of their hydrophobic cages, framework flexibility, and considerable chemical and thermal stability. ${ }^{21}$ Hundreds of ZIF structures have been synthesized to date. ${ }^{19,20}$ However, with use of the 4,5-dichloroimidazolate (dcim) linker, until now only two ZIF polymorphs have been synthesized directly, microporous RHO-type ZIF-71 and nonporous lcs-type ZIF-72. ${ }^{20}$ The corresponding $\left[\mathrm{Zn}(\mathrm{dcim})_{2}\right]$-SOD has been obtained indirectly via solvent-assisted ligand exchange ${ }^{22}$ or modulated synthesis. ${ }^{23}$ To the best of our knowledge, a direct one-pot synthesis of $\mathrm{Zn}(\mathrm{dcim})_{2}$ with SOD topology has not yet been reported.

Received: August 19, 2020

Published: February 16, 2021 


\section{RESULTS AND DISCUSSION}

Synthesis, Characterization and Gas Adsorption Properties. Phase-pure $\mathrm{Zn}(\mathrm{dcim})_{2}$, coined COK-17 (COK17: Centrum voor Oppervlaktechemie en Katalyse No. 17), with SOD topology was obtained by direct one-pot solvothermal synthesis. COK-17 crystallizes from a zinc nitrate and 4,5-dichloroimidazoleDMF/water solvent mixture. Scanning electron microscopy (SEM) shows COK-17 crystals as well-defined, micrometer-sized rhombohedra (Figure S1, Supporting Information). The high crystallinity of the material was confirmed by X-ray diffraction (XRD, Figure 1). The

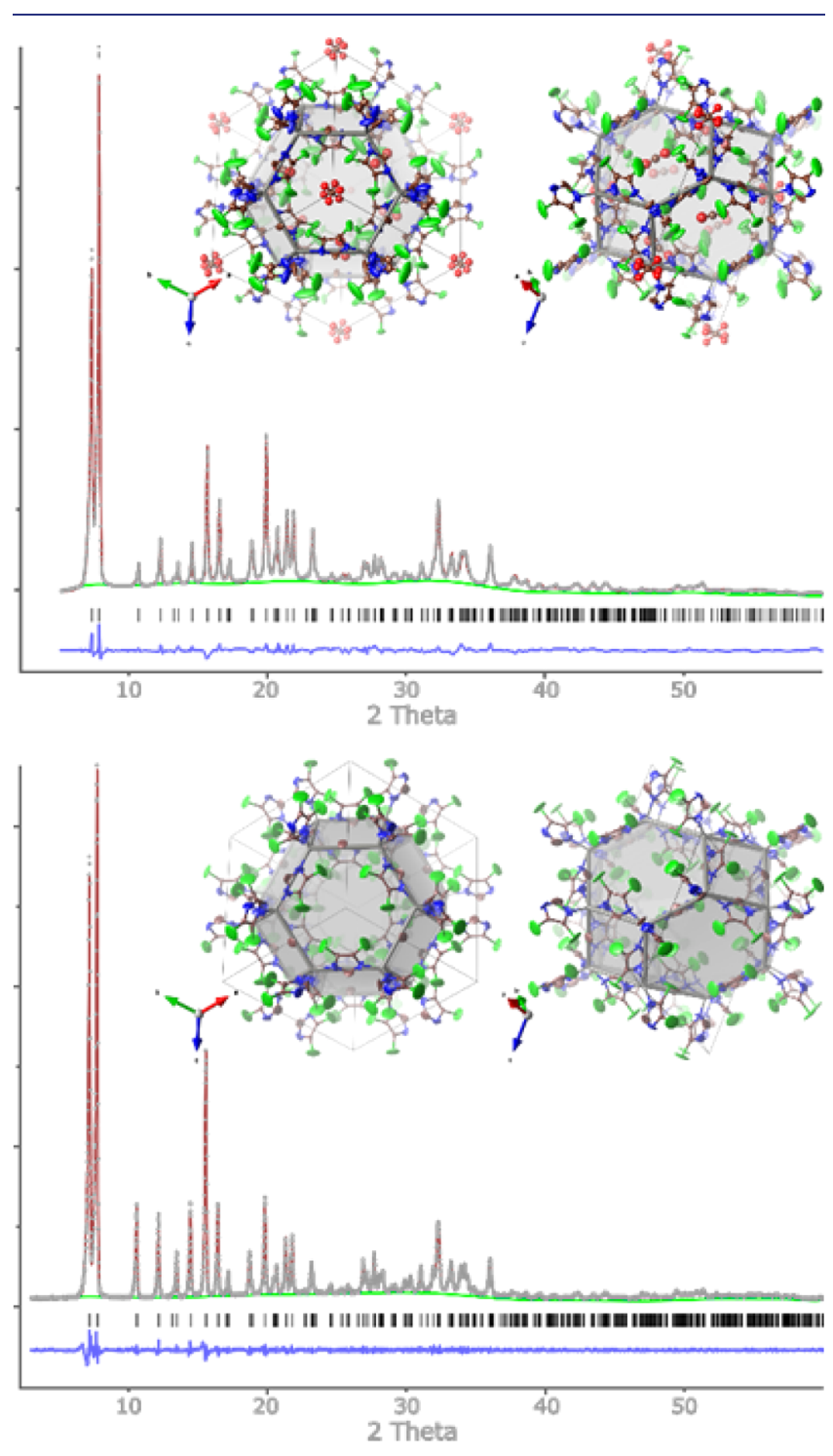

Figure 1. Room temperature XRD pattern and Rietveld refinement of $\mathrm{Zn}$ (dcim) ${ }_{2}$ COK-17. Rietveld refinements of activated COK-17 (bottom) and saturated with $\mathrm{CO}_{2}$ at a pressure of 1 bar and a temperature of $293 \mathrm{~K}$ (top). Framework with highlighted SOD-type cage are shown in the insets.

diffractogram could be excellently described in the rhombohedral space group $R \overline{3}$ with $a=b=c=14.10 \AA$ and $\alpha=\beta=\Upsilon=$ $107.23^{\circ}$. Rietveld refinement ${ }^{24,25}$ revealed the SOD topology with the same arrangement of cations and linkers as found in ZIF-8, but elongated along the space diagonal of the cubic structure, resulting in the decreased angle of $107.23^{\circ}$ between the rhombohedral axes (Figure 1, inset, see Supporting Information for more details). COK-17 is thermally stable up to $673 \mathrm{~K}$ in nitrogen, according to thermogravimetric analysis (Figure S2). COK-17 is stable for at least 2 years when stored under ambient humidity. Line broadening of the Bragg reflections indicated the rhombhedral angle varied in the stored sample. After activation at $150{ }^{\circ} \mathrm{C}$ in vacuum, the sample returned to its original behavior. Exposure of COK-17 to water at room temperature shows no effect, while upon steaming the unit cell expands to pseudocubic dimensions, though it still is best described in the original rhombohedral space group $R \overline{3}$ (see Figure S3). Modeling the structure using the FOX simulation software, ${ }^{26}$ using an unstructured electron density in a large cage, resulted in an excellent fit of the data, demonstrating the connectivity between the linker and $\mathrm{Zn}$ ions persisting during steaming.

According to the structure determination by Rietveld refinement, COK-17 at room temperature is always observed in its open-pore state, independent of whether it is fully evacuated or contains adsorbed molecules. The potential occurrence of structural flexibility of the empty COK-17 framework was investigated by force-field-based molecular dynamics simulations at different temperatures and pressures, a method that was shown to provide accurate information on the flexibility of MOFs. ${ }^{27}$ The free energy of the empty COK-17 framework as a function of its unit cell volume at different temperatures and pressures was estimated, following the procedure explained in the Supporting Information (see computational section "Force field simulations"). ${ }^{28}$ The resulting free energy profiles at various temperatures (Figure S4 and Table S1) clearly reveal that the open-pore phase is the only stable phase at temperatures above $200 \mathrm{~K}$. At lower temperatures, a metastable closed-pore phase appears next to the stable open-pore phase. As a result, host-guest interactions may steer the system from its open-pore phase to the closedpore phase upon adsorption at low temperatures, even though the closed-pore phase of the empty host remains less stable than its open-pore state. The occurrence of such a structural variation was also hinted at by the observation of a stepped Type I $\mathrm{N}_{2}$ adsorption isotherm at a temperature of $77 \mathrm{~K}$ (Figure S5). Two distinctive steps with hystereses are observed in the relative pressure $\left(P / P_{0}\right)$ range of $0.15-0.25$ and $0.5-0.8$, respectively. In flexible frameworks, such behavior can be due to framework rearrangement and reorganization of the adsorbate. ${ }^{29-31}$ The peculiar double-stepped adsorption profile indicates a similar breathing mechanism as recently reported for the isostructural $\mathrm{Zn}(\mathrm{dcim})_{2}$-SOD material, which also shows two different hysteresis loops in argon physisorption. ${ }^{23}$ According to the $\mathrm{N}_{2}$ adsorption branch, the low-temperature form of COK-17 has a micropore volume of $0.26 \mathrm{~cm}^{3} \mathrm{~g}^{-1}$ (plateau I of the isotherm in Figure S5a) and a micropore diameter of $1.2 \mathrm{~nm}$ according to nonlinear density functional theory. Brunauer-Emmet-Teller (BET) and Langmuir specific surface areas amount to 500 and $628 \mathrm{~m}^{2} \mathrm{~g}^{-1}$, respectively.

Adsorption of $\mathrm{CO}_{2}$ and $\mathrm{CH}_{4}$ molecules on $\mathrm{COK}-17$ powder at ambient temperature was investigated by determination of adsorption isotherms for $\mathrm{CH}_{4}$ and $\mathrm{CO}_{2}$, by powder $\mathrm{XRD}$ and structure refinement of COK-17 saturated at 1 bar pressure with the two gases, and by computational modeling. The experimental adsorption isotherms (Figure 2a) reveal the high affinity of COK-17 for $\mathrm{CO}_{2}$ and $\mathrm{CH}_{4}$, with uptakes at $1 \mathrm{bar}$ and $298 \mathrm{~K}$ of 2.5 and $1.24 \mathrm{mmol} \mathrm{g}^{-1}$, respectively. These values are 

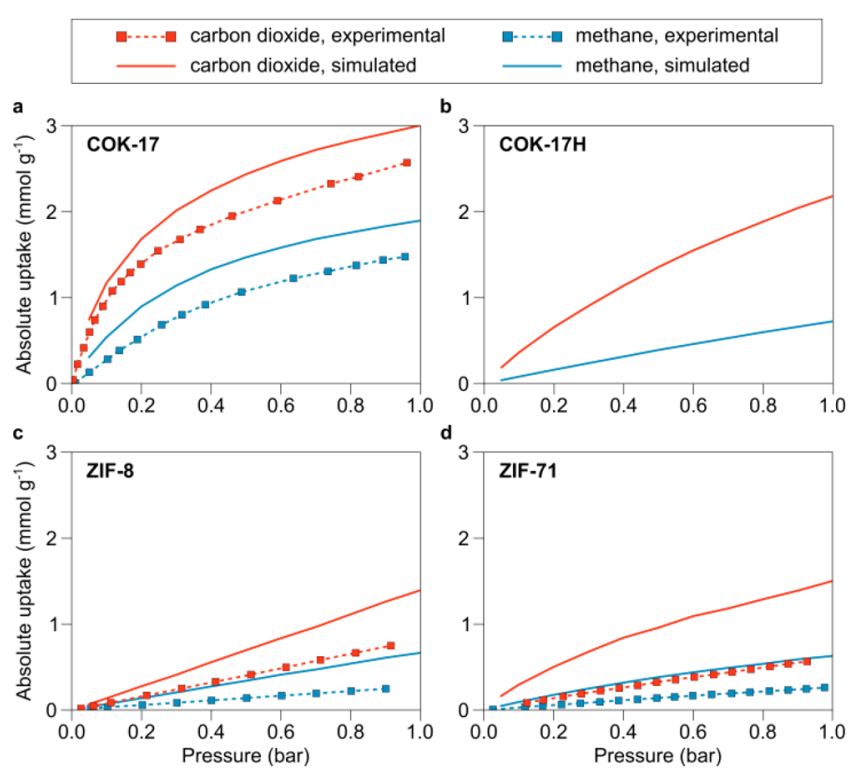

Figure 2. Experimental and simulated single-component adsorption isotherms of $\mathrm{CO}_{2}$ and $\mathrm{CH}_{4}$ collected at $298 \mathrm{~K}$. Experimental (dotted lines with symbols) and computationally simulated (full lines) adsorption isotherms of $\mathrm{CO}_{2}$ and $\mathrm{CH}_{4}$ on (a) COK-17, (b) a hypothetical isostructural $\mathrm{COK}-17 \mathrm{H}$ framework with $\mathrm{Cl}$ atoms systematically replaced with $\mathrm{H}$ atoms, and (c) ZIF-8 and (d) ZIF71 benchmark materials for which experimental adsorption data were taken from refs 33 34, and36

much higher compared to those of related ZIF materials, like ZIF-8, where corresponding $\mathrm{CO}_{2}$ and $\mathrm{CH}_{4}$ uptakes are limited to 0.7 and $0.25 \mathrm{mmol} \mathrm{g}^{-1}$, and ZIF-71 with uptakes of 0.6 and $0.27 \mathrm{mmol} \mathrm{g}^{-1}$ only (Figures $\left.2 \mathrm{c}, \mathrm{d}\right) .^{32-35}$ Breakthrough separation experiments on COK-17, performed at $303 \mathrm{~K}$, revealed its separation performance for binary gas $\mathrm{CO}_{2} / \mathrm{CH}_{4}$ mixtures with different compositions $\left(\mathrm{CO}_{2} / \mathrm{CH}_{4}=20: 80\right.$ and $50: 50 \mathrm{v} / \mathrm{v}$ ) (Figure $\mathrm{S} 6$ in the Supporting Information). The effluent from the bed was monitored by mass spectrometry. The breakthrough curves show pure $\mathrm{CH}_{4}$ as the first eluent, indicating a high selectivity of COK-17 for $\mathrm{CO}_{2}$ over $\mathrm{CH}_{4}$ under flow conditions. The retention time for $\mathrm{CH}_{4}$ over $\mathrm{COK}$ 17 was $100 \mathrm{~s}$ in $\mathrm{CO}_{2} / \mathrm{CH}_{4}(20: 80)$ mixed-gas flow versus $50 \mathrm{~s}$ in an equimolar $\mathrm{CO}_{2} / \mathrm{CH}_{4}$ mixture. These values correspond to $\mathrm{CO}_{2}$ adsorption capacities of 0.40 and $0.50 \mathrm{mmol} \mathrm{g}^{-1}$ at 303 $\mathrm{K}$ and partial pressures of 0.2 and 0.5 bar, respectively.

We calculated the isosteric heats of $\mathrm{CO}_{2}$ adsorption for COK-17, according to the Clausius-Clapeyron eq (eq 1) from the adsorption isotherms measured at 273 and $298 \mathrm{~K}$ :

$$
q_{\text {st }}=-R[\Delta(\ln P) / \Delta(1 / T)] N
$$

where $q_{\mathrm{st}}, R, P, T$, and $N$ correspond to isosteric heat of adsorption, gas constant, pressure, temperature, and amount of adsorbed $\mathrm{CO}_{2}$, respectively. The results are presented in Figure S7 and in agreement with a diminution of the heat of adsorption with increasing surface coverage, which agrees with the proposed physisorption process. The obtained values $\left(-28.5\right.$ to $\left.-23.5 \mathrm{~kJ} \mathrm{~mol}^{-1}\right)$ are in agreement with the DFT calculation values for the nondistorted structure.

Host-Guest Interaction. The $\mathrm{CO}_{2}$ and $\mathrm{CH}_{4}$ adsorption isotherms on COK-17 at $298 \mathrm{~K}$ did not show any steps that would indicate a structure change upon adsorption (Figure 2a, Figures S8 and S9). Given the large uptake, localization of the adsorbed $\mathrm{CO}_{2}$ molecules by Rietveld refinement of X-ray diffraction data was feasible, as shown in Figure $1 .^{24,25}$ The diffraction experiments clearly indicated two possible positions for adsorbed $\mathrm{CO}_{2}$, which are situated in the symmetric and the distorted 6-ring (6R) windows of the SOD cavities, located at the origin and the faces of the rhombohedral unit cell, respectively (Figure 3 ). While the symmetric 6-ring (site A)

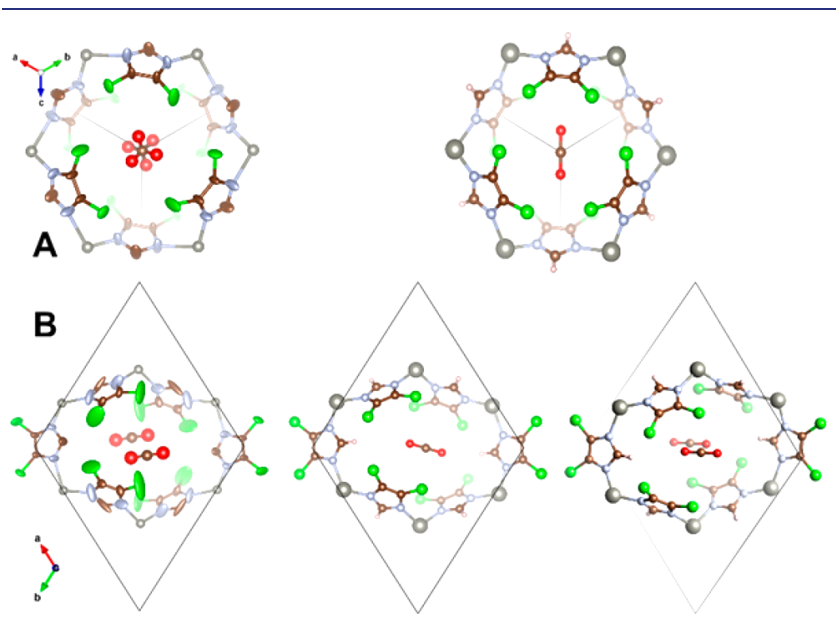

Figure 3. $\mathrm{CO}_{2}$ sites in $\mathrm{COK}-17$. Top row: adsorption site $\mathrm{A}$ for $\mathrm{CO}_{2}$ in symmetric $6 \mathrm{R}$ of $\mathrm{COK}-17$ (left, experiment; right, simulation). Bottom row: adsorption sites(s) B for $\mathrm{CO}_{2}$ in distorted $6 \mathrm{R}$ of COK17 (left, experiment; middle and right, simulation).

contains only one $\mathrm{CO}_{2}$ molecule, two crystallographically equivalent sites for $\mathrm{CO}_{2}$ were found in the distorted rings (site B), which are both occupied simultaneously by a guest molecule at a pressure of 1 bar (Figure 3). Refinement of the structure of COK-17 loaded with $\mathrm{CO}_{2}$ at 1 bar revealed an overall loading of ca. $0.7 \quad \mathrm{CO}_{2}$ molecules per $\mathrm{Zn}(\mathrm{dcim})_{2}$ formula, in agreement with the experimental value of ca. 0.8 . The theoretical maximum with all sites $\mathrm{A}$ and $\mathrm{B}$ occupied corresponds to $1.0 \mathrm{CO}_{2}$ per $\mathrm{Zn}(\mathrm{dcim})_{2}$.

Further insight in the adsorption sites was obtained from periodic density functional theory (DFT) calculations performed on the experimentally determined unit cell of the COK-17 lattice. Stable adsorption sites of 1 molecule of $\mathrm{CO}_{2}$ on sites $\mathrm{A}$ and $\mathrm{B}$ were found with similar adsorption energies, namely, $E_{\mathrm{ads}}=-28 \mathrm{~kJ} \mathrm{~mol}^{-1}$ on site $\mathrm{A}$ and $E_{\mathrm{ads}}=-31 \mathrm{~kJ} \mathrm{~mol}^{-1}$ on site B. This allows them to appear identical in an experimental adsorption process so that both sites are expected to contribute simultaneously to $\mathrm{CO}_{2}$ adsorption. A similar conclusion for $\mathrm{CH}_{4}$ can be drawn: at site $\mathrm{A}$ an adsorption energy of $-25 \mathrm{~kJ} \mathrm{~mol}^{-1}$ is calculated, while at site B a slightly more stable value of $-27 \mathrm{~kJ} \mathrm{~mol}^{-1}$ is found. As the singlemolecule adsorption energies favor $\mathrm{CO}_{2}$ over $\mathrm{CH}_{4}$, it can already be inferred that $\mathrm{CO}_{2}$ will certainly be preferably adsorbed at low pressures, which is discussed in more detail later on (vide infra).

The adsorption of two $\mathrm{CO}_{2}$ molecules in the distorted 6Rs of site $\mathrm{B}$ was simulated next. A distinct energetic minimum upon adsorption of two molecules in position B, closely resembling the refined structure, was found (Figure 3 ). The total adsorption energy for this configuration amounts to -55 $\mathrm{kJ} \mathrm{mol}^{-1}$, which should result in a free energy release of $24 \mathrm{~kJ}$ $\mathrm{mol}^{-1}$ upon adsorption of the second molecule on site B, assuming the first molecule contributes $-31 \mathrm{~kJ} \mathrm{~mol}^{-1}$. Interestingly, the large cage of COK-17 appeared empty in the diffraction study and showed significantly lower stabiliza- 
tion of $\mathrm{CO}_{2}$ molecules by DFT as compared to sites A and B. In accordance with simulation and structure determination, the experimental adsorption isotherm for $\mathrm{CO}_{2}$ on COK-17 could not be fitted with a single-site Langmuir model (Figure S10), but only be described with a dual-site model with different adsorption energies. In contrast, the adsorption of the larger $\mathrm{CH}_{4}$ molecule on COK-17 could be well described by a singlesite Langmuir model.

Molecular Simulations. The exceptional adsorption performance of COK-17 compared to ZIF-8 and ZIF-71 (Figure 2) suggests that the presence of $\mathrm{Cl}$ atoms in the imidazole linkers is responsible for the strong adsorption on sites $\mathrm{A}$ and B. For an understanding of the exceptional behavior of COK-17 in terms of its structure and $\mathrm{Cl}$ content, adsorption capacities were simulated for four different ZIF frameworks, which all contain 6-rings, though with different chemical functionalities and/or topologies (see Table S2). Like COK-17, ZIF-8 with 2-methylimidazole linkers displays the SOD topology but in a cubic undistorted configuration. ZIF71 , on the other hand, shows the same chlorinated linkers as COK-17, but manifests in the RHO rather than in the SOD topology. For specifically the gaining of insight into the effect of the $\mathrm{Cl}$ substituents, a purely theoretical framework with the same structure as $\mathrm{COK}-17$ but with the $\mathrm{Cl}$ atoms substituted with $\mathrm{H}$ atoms was also investigated. Hereafter, this structure will be referred to as $\mathrm{COK}-17 \mathrm{H}$.

The adsorption isotherms of $\mathrm{CO}_{2}$ and $\mathrm{CH}_{4}$ in $\mathrm{COK}-17$, COK-17H, ZIF-8, and ZIF-71 were estimated using grand canonical Monte Carlo (GCMC) simulations with rigid frameworks according to their experimental geometry and using the Dreiding-MBIS/TraPPE model (for more details, see the Supporting Information). The simulated values show the same trends as the experimental isotherms, although they slightly overestimate the experimental observations, especially for ZIF-71. COK-17 outperforms COK-17H, ZIF-8, and ZIF71 with respect to the affinity for $\mathrm{CO}_{2}$ and methane. All frameworks systematically show a higher adsorption capacity for $\mathrm{CO}_{2}$ compared to $\mathrm{CH}_{4}$.

Minimum energy locations of the guest molecules computed for COK-17, COK-17H, ZIF-8, and ZIF-71 highlight the differences even further. Of all these frameworks only the linker conformation in COK-17 shows inversion centers in the $6 \mathrm{R}$ of the structure (Figure 4). This leads to the formation of two-sided cradles formed from six or four linkers on sites $\mathrm{A}$ and B, respectively (Figure 4). In ZIF-71 only one-sided cradles are expressed in the 6Rs, while in ZIF- 8 the three linkers in the $6 \mathrm{Rs}$ are in an almost coplanar arrangement with the ring (Figure 4). Energy minimization by DFT revealed that the low energy configuration of $\mathrm{CO}_{2}$ in both frameworks is not located in the $6 \mathrm{Rs}$, but in the large cavities, close to a $4 \mathrm{R}$ in ZIF-71 and at a rather unspecific site for ZIF-8 (Figure 4). ZIF-8 shows no expressed energetic minimum in the structure at large, with the configurations of $\mathrm{CO}_{2}$ in the $6 \mathrm{Rs}$ similar in energy compared to the global minimal energy in the large cavities. The adsorption energies for all sites are listed in Table S3.

The contribution of London dispersion to the adsorption energy (Table S3 in the Supporting Information) shows that London dispersion forces dominate the adsorption energies irrespective of the particular framework. Among all sites in the different ZIFs, the distorted 6-rings in COK-17 have the highest $\mathrm{CO}_{2}$ adsorption energy $\left(-31 \mathrm{~kJ} \mathrm{~mol}^{-1}\right)$ and the highest London dispersion interaction $\left(-28 \mathrm{~kJ} \mathrm{~mol}^{-1}\right)$. The presence

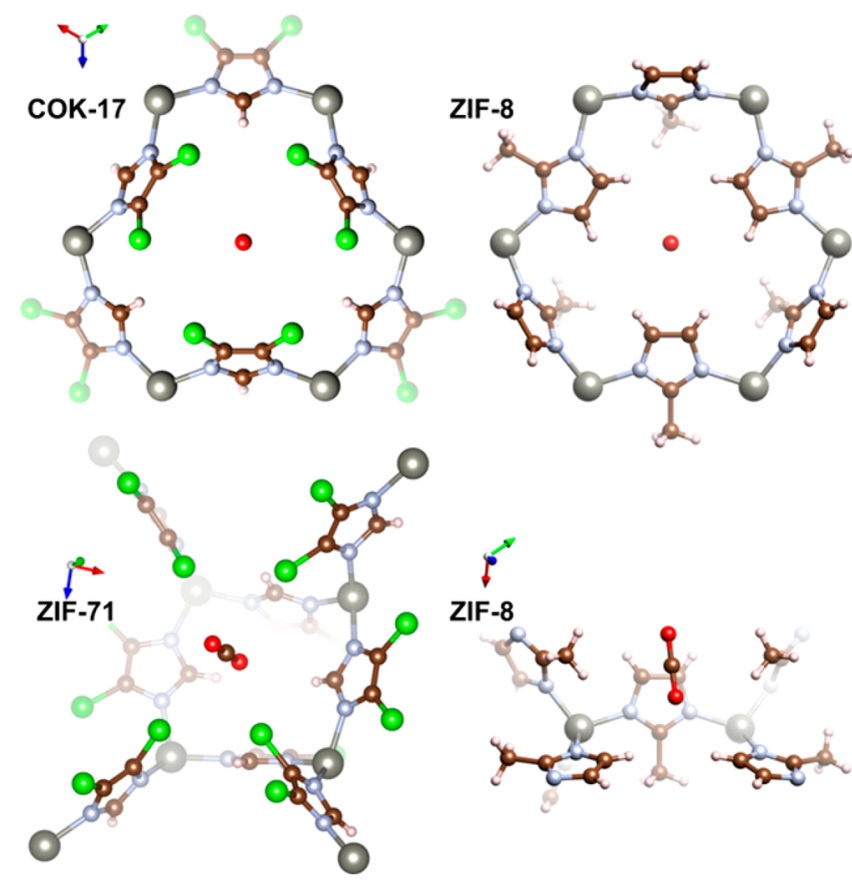

Figure 4. Adsorption sites of $\mathrm{CO}_{2}$ as determined from simulations. Top left, 6R COK-17; top right, 6R ZIF-8. Bottom left, 4R ZIF-71; bottom right, large cage ZIF-8.

of $\mathrm{Cl}$ substituents on the imidazole linker leads to increased van der Waals (vdW) interactions by the enhanced dispersion forces of the electron-rich $\mathrm{Cl}$ atom as compared to that of $\mathrm{N}$, $\mathrm{C}$, and $\mathrm{H}$ atoms of imidazolate linkers devoid of it. COK-17H has the same structure as $\mathrm{COK}-17$, but does not feature $\mathrm{Cl}$ substituents. DFT calculations for molecules on sites A and B in symmetric and distorted 6-rings systematically revealed increased adsorption energies in the presence of $\mathrm{Cl}$-substituted linkers, especially for $\mathrm{CO}_{2}$ on site $\mathrm{B}$, but even more strongly for $\mathrm{CH}_{4}$ on both sites, highlighting the impact of chlorination.

Figure 5a shows the selectivities of $\mathrm{CO}_{2}$ versus $\mathrm{CH}_{4}$, extracted from GCMC simulations of $\mathrm{CO}_{2} / \mathrm{CH}_{4}$ mixtures with different compositions. As a reference, also the experimental selectivities derived from the measurement of singlecomponent adsorption isotherms using the Ideal Adsorbed Solution Theory (IAST) are shown. ${ }^{37}$ The $\mathrm{CO}_{2}$ selectivity of ZIF-8 is the lowest, followed by ZIF-71. Both show only slight variations with respect to pressure or composition. COK-17 exhibits varied $\mathrm{CO}_{2} / \mathrm{CH}_{4}$ selectivities depending on $\mathrm{CO}_{2} / \mathrm{CH}_{4}$ ratios. The $\mathrm{CO}_{2} / \mathrm{CH}_{4}$ mixture composition does not affect the $\mathrm{CO}_{2} / \mathrm{CH}_{4}$ selectivity of ZIF-8 nor of ZIF-71. COK-17 shows the highest selectivity, which, interestingly, increases with pressure and significantly depends on the $\mathrm{CO}_{2}$ content. For instance, the calculated mixed-gas selectivity of COK-17 at 1 bar in a 80:20 binary $\mathrm{CO}_{2} / \mathrm{CH}_{4}$ mixture composition was 4 , while a 50:50 mixture gave a slightly decreased selectivity of 3.5 , followed by a selectivity of 3.25 achieved in a 20:80 binary $\mathrm{CO}_{2} / \mathrm{CH}_{4}$ mixture. The ideal selectivity of $\mathrm{CO}_{2}$ over $\mathrm{CH}_{4}$ increases at higher pressures from 1 to 10 bar for different $\mathrm{CO}_{2} / \mathrm{CH}_{4}$ mixtures according to the results obtained using GCMC simulations. Similarly, the simulation results demonstrate that lower $\mathrm{CO}_{2} / \mathrm{CH}_{4}$ selectivities were obtained for COK-17 in the mixtures containing an excess of methane. For instance, the calculated ideal selectivity of COK-17 at 10 bar in a 80:20 binary $\mathrm{CO}_{2} / \mathrm{CH}_{4}$ mixture was 7.8 , while a 50:50 mixture gave a slightly decreased selectivity of 7.0 based on 

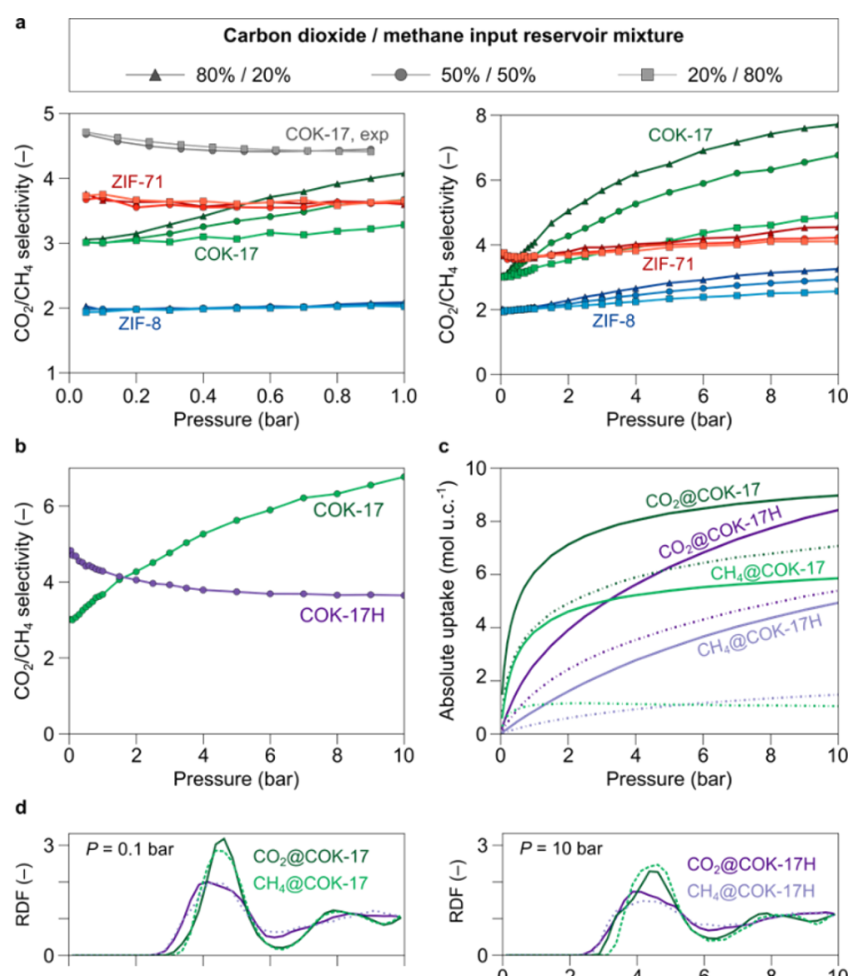

Distance $(\AA)$
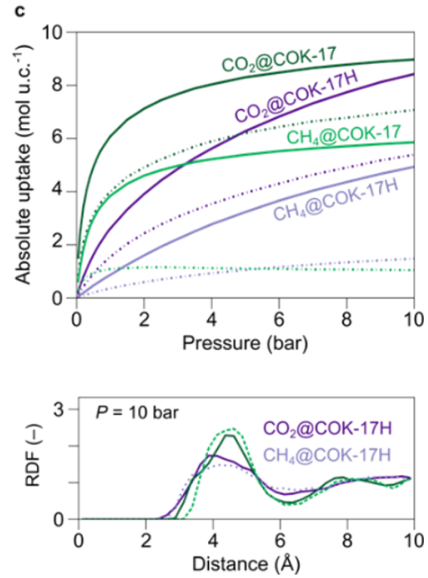

Figure 5. Mixed-gas $\mathrm{CO}_{2} / \mathrm{CH}_{4}$ selectivity. (a) Static selectivity of $\mathrm{CO}_{2}$ over $\mathrm{CH}_{4}$ as modeled via GCMC simulations when the framework is in contact with a reservoir of the $\mathrm{CO}_{2} / \mathrm{CH}_{4}$ mixture at different volume ratios of 80:20, 50:50, and 20:80 (v/v) and at different pressure ranges from 0 bar to either 1 or 10 bar. (b) Selectivity of $\mathrm{CO}_{2}$ over $\mathrm{CH}_{4}$ for a 50:50 mixture obtained using GCMC. (c) Adsorption isotherms of pure components (full lines) and a 50:50 mixture (dotted lines) obtained using GCMC. (d) Radial distribution functions between the center-of-mass of the guest molecules and the chlorine atoms of $\mathrm{COK}-17$ versus the corresponding hydrogen atoms of $\mathrm{COK}-17 \mathrm{H}$ and at pressures of either 0.1 or 10 bar.

GCMC simulations. At very low pressures, the selectivity can be estimated from the Boltzmann weights of the adsorption energies for the most stable adsorption sites:

$$
\alpha_{\mathrm{CO}_{2} / \mathrm{CH}_{4}} \approx \mathrm{e}^{-\beta\left(\mathrm{Eds}, \mathrm{CO}_{2}-E_{\mathrm{ads}, \mathrm{CH}}^{\min }\right)}
$$

$E_{\mathrm{ads}, \mathrm{CO}_{2}}^{\min }$ and $E_{\mathrm{ads}, \mathrm{CH}_{4}}^{\min }$ being the adsorption energies of the most stable sites for $\mathrm{CO}_{2}$ and $\mathrm{CH}_{4}$, respectively. For $\mathrm{COK}-17$, the energy difference amounts to $-4 \mathrm{~kJ} \mathrm{~mol}^{-1}$, while for COK-17H an even higher value of $-7 \mathrm{~kJ} \mathrm{~mol}^{-1}$ is obtained. On the basis of this analysis, a higher selectivity in $\mathrm{COK}-17 \mathrm{H}$ compared to that in COK-17 is expected. While the chlorine atoms in COK17 apparently stabilize the $\mathrm{CO}_{2}$ guests, the same is true to an even higher extent for $\mathrm{CH}_{4}$. This astonishing result is in apparent contradiction with the hypothesis that increased and preferential $\mathrm{vdW}$ interactions of the chlorinated linkers with $\mathrm{CO}_{2}$ leads to the very high selectivity of COK-17 for $\mathrm{CO}_{2}$, as observed by experiment as well as simulation. This result together with the selectivity dependence on pressure and particular $\mathrm{CO}_{2} / \mathrm{CH}_{4}$ composition urged us to investigate the competition and/or synergy of the guest molecules using a force-field methodology. The selectivity, obtained from a GCMC simulation of a 50:50 (v/v) $\mathrm{CO}_{2} / \mathrm{CH}_{4}$ mixture, as a function of the pressure of the gas mixture is shown in Figure 5b. At low pressures $\mathrm{COK}-17 \mathrm{H}$ indeed shows higher selectivity. Interestingly, the $\mathrm{COK}-17 \mathrm{H}$ selectivity decreases with increasing pressure, while for COK-17 the inverse is true. The curves cross at a pressure of about 2 bar. The behavior can be better understood by analysis of the separate components during simulation, shown by dotted lines in Figure 5c.

For COK-17, Figure $5 \mathrm{c}$ reveals that the uptake of $\mathrm{CH}_{4}$ in the mixture saturates already below a pressure of 1 bar. This means that, above a certain pressure, $\mathrm{CO}_{2}$ molecules win the competition for the remaining adsorption sites. As the $\mathrm{CO}_{2}$ uptake increases while the $\mathrm{CH}_{4}$ uptake remains constant, obviously selectivity increases. For COK-17H, both $\mathrm{CO}_{2}$ and $\mathrm{CH}_{4}$ loadings are still increasing at a pressure of 10 bar. This can be related to the much higher surface area and pore volume of $\mathrm{COK}-17 \mathrm{H}$ compared to those of $\mathrm{COK}-17$ as a consequence of the presence of the large chlorine atoms being replaced by hydrogen in $\mathrm{COK}-17 \mathrm{H}$. At higher pressures there is still enough free space in $\mathrm{COK}-17 \mathrm{H}$ for both, $\mathrm{CO}_{2}$ and $\mathrm{CH}_{4}$ molecules, to adsorb. But in $\mathrm{COK}-17$, the smaller pore volume prevents efficient packing of the almost spherical $\mathrm{CH}_{4}$ molecules, so saturation already occurs at low loadings. These results are in full agreement with the observation that the favored adsorption site $\mathrm{B}$ in COK-17 can be occupied by only one $\mathrm{CH}_{4}$ molecule, but by two $\mathrm{CO}_{2}$ molecules, which also led to the necessity to assume a two-site model for the description of the adsorption isotherm (vide supra).

Moreover, the radial distribution functions ( $\mathrm{RDFs}$ ) of $\mathrm{Cl}$ around the guest molecules at 0.1 and 10 bar obtained from snapshots of guest-molecule configurations extracted from GCMC simulations of mixtures clearly rules out preferred vdW interactions with $\mathrm{CO}_{2}$ as the sole cause for high selectivities at low pressures (Figure 5d). The similarity of $\mathrm{CO}_{2}$ and $\mathrm{CH}_{4}$ RDFs confirms that both molecules compete for the same adsorption sites. In $\mathrm{COK}-17$, the peaks are higher and more defined compared to those of $\mathrm{COK}-17 \mathrm{H}$, indicating more locally defined adsorption sites. Interestingly, a comparison of RDFs obtained from simulations at 0.1 and 10 bar reveals a shoulder of the $\mathrm{CO}_{2} \mathrm{RDF}$ of $\mathrm{COK}-17$, not present at very low pressures and starting to emerge at 1 bar. At higher pressure and higher total loading, $\mathrm{CO}_{2}$ occupies site $\mathrm{B}$, with two molecules in close contact with the chlorine atoms, while these sites are not accessible for more than a single $\mathrm{CH}_{4}$. Increased proximity to $\mathrm{Cl}$ leads to significant gain in interaction energy and clearly can be related to the more efficient packing of $\mathrm{CO}_{2}$ with increasing pressure.

\section{CONCLUSIONS}

COK-17 zeolitic-imidazolate framework with $\mathrm{Zn}$ ions bridged by 4,5-dichloroimidazolate has a permanent microporosity and is highly selective for $\mathrm{CO}_{2}$ adsorption. $\mathrm{CO}_{2}$ and $\mathrm{CH}_{4}$ compete for the same adsorption sites, but the smaller $\mathrm{CO}_{2}$ molecules win the competition because they can pack more densely in higher numbers, maximizing their van der Waals interaction. $\mathrm{CO}_{2}$ molecules, neatly fitting into the cavities this way, exclude the uptake of $\mathrm{CH}_{4}$. Insight from the refined structure and molecular simulations explain the details of the adsorption isotherms of the individual molecules as well as the mixtures. The favored adsorption site can be occupied by only one $\mathrm{CH}_{4}$ molecule but by two $\mathrm{CO}_{2}$ molecules, explaining the necessity to assume a two-site model for the description of the $\mathrm{CO}_{2}$ adsorption isotherm. On the basis of this insight, COK-17 could potentially be used to improve the separation of $\mathrm{CO}_{2}$ 
from other molecules where the van der Waals interaction is a dominant mechanism.

\section{ASSOCIATED CONTENT}

\section{SI Supporting Information}

The Supporting Information is available free of charge at https://pubs.acs.org/doi/10.1021/jacs.0c08942.

Synthesis and characterization methods, SEM image, TG profile, free energy and pressure equations of state, OPto- $\mathrm{CP}$ and $\mathrm{CP}$-to-OP transition pressures, gas adsorption-desorption isotherms, DFT and $\mathrm{BJH}$ pore size distribution curves, breakthrough curves, single-site and dual-site Langmuir isotherms for $\mathrm{CH}_{4}$ and $\mathrm{CO}_{2}$, framework properties, simulated adsorption energies, and contribution of London dispersion (PDF)

\section{Accession Codes}

CCDC 2057222-2057223 contain the additional crystallographic data for this paper. These data can be obtained free of charge via www.ccdc.cam.ac.uk/data_request/cif, or by emailing data_request@ccdc.cam.ac.uk, or by contacting The Cambridge Crystallographic Data Centre, 12 Union Road, Cambridge CB2 1EZ, UK; fax: +44 1223336033.

\section{AUTHOR INFORMATION}

\section{Corresponding Authors}

Lik H. Wee - Centre for Surface Chemistry and Catalysis Characterisation and Application Team (COK-kat), KU Leuven, Leuven B3001, Belgium; (1) orcid.org/0000-00017343-3833; Email: 1hw31@cam.ac.uk

Christine E. A. Kirschhock - Centre for Surface Chemistry and Catalysis Characterisation and Application Team (COK-kat), KU Leuven, Leuven B3001, Belgium; Email: christine.kirschhock@kuleuven.be

\section{Authors}

Steven Vandenbrande - Center for Molecular Modeling (CMM), Ghent University, Zwijnaarde 9052, Belgium

Sven M. J. Rogge - Center for Molecular Modeling (CMM), Ghent University, Zwijnaarde 9052, Belgium; 이잉.org/ 0000-0003-4493-5708

Jelle Wieme - Center for Molecular Modeling (CMM), Ghent University, Zwijnaarde 9052, Belgium; ○ orcid.org/00000002-4841-2608

Karel Asselman - Centre for Surface Chemistry and Catalysis Characterisation and Application Team (COK-kat), KU Leuven, Leuven B3001, Belgium

Erika O. Jardim - Laboratorio de Materiales Avanzados, Departamento de Química Inorgánica-Instituto Universitario de Materiales, Universidad de Alicante, San Vicente del Raspeig E-03690, Spain

Joaquin Silvestre-Albero - Laboratorio de Materiales Avanzados, Departamento de Química Inorgánica-Instituto Universitario de Materiales, Universidad de Alicante, San Vicente del Raspeig E-03690, Spain; (1) orcid.org/00000002-0303-0817

Jorge A. R. Navarro - Departamento de Química Inorgánica, Universidad de Granada, Granada 18071, Spain; (i) orcid.org/0000-0002-8359-0397

Veronique Van Speybroeck - Center for Molecular Modeling (CMM), Ghent University, Zwijnaarde 9052, Belgium; (1) orcid.org/0000-0003-2206-178X
Johan A. Martens - Centre for Surface Chemistry and Catalysis Characterisation and Application Team (COKkat), KU Leuven, Leuven B3001, Belgium

Complete contact information is available at: https://pubs.acs.org/10.1021/jacs.0c08942

\section{Author Contributions}

The manuscript was written through contributions of all authors. All authors have given approval to the final version of the manuscript.

Notes

The authors declare no competing financial interest.

\section{ACKNOWLEDGMENTS}

L.H.W. acknowledges the Fonds Wetenschappelijk Onderzoek (FWO) - Vlaanderen for a senior postdoctoral research fellowship and International Mobility fellowship under contract numbers of $12 \mathrm{M} 1418 \mathrm{~N}$ and V402319N, respectively. S.V.D.B., S.M.J.R., and J.W. acknowledge Fonds Wetenschappelijk Onderzoek (FWO) - Vlaanderen for Grants 11U1914N, $12 \mathrm{~T} 3519 \mathrm{~N}$, and $1103618 \mathrm{~N}$ as well as the Research Board of Ghent University (BOF). J.A.R.N. acknowledges generous funding from the Spanish Ministry of Economy (CTQ201453486-R) and FEDER from the European Union. Funding was also received from the European Union's Horizon 2020 Research and Innovation Programme [ERC Consolidator Grant Agreement 647755 - DYNPOR (2015-2020)]. J.A.M. and C.E.A.K. gratefully acknowledge financial support from the Flemish Government (Long-term structural funding Methusalem and FWO support). Collaboration among universities was supported by the Belgian Government (IAP-PAI network).

\section{REFERENCES}

(1) Bae, Y.-S.; Snurr, R. Q. Development and evaluation of porous materials for carbon dioxide separation and capture. Angew. Chem., Int. Ed. 2011, 50, 11586-11596.

(2) Markewitz, P.; Kuckshinrichs, W.; Leitner, W.; Linssen, J.; Zapp, P.; Bongartz, R.; Schreiber, A.; Müller, T. E. Worldwide innovations in the development of carbon capture technologies and the utilization of $\mathrm{CO}_{2}$. Energy Environ. Sci. 2012, 5, 7281-7305.

(3) Martens, J. A.; Bogaerts, A.; De Kimpe, N.; Jacobs, P. A.; Marin, G. B.; Rabaey, K.; Saeys, M.; Verhelst, S. The chemical route to a carbon dioxide neutral world. ChemSusChem 2017, 10, 1039-1055.

(4) Li, J.-R.; Kuppler, R. J.; Zhou, H.-C. Selective gas adsorption and separation in metal-organic frameworks. Chem. Soc. Rev. 2009, 38, $1477-1504$

(5) Duan, J.; Jin, W.; Kitagawa, S. Water-resistant porous coordination polymers for gas separation. Coord. Chem. Rev. 2017, $332,48-74$.

(6) Sumida, K.; Rogow, D. L.; Mason, J. A.; McDonald, T. M.; Bloch, E. D.; Herm, Z. R.; Bae, T.-H.; Long, J. R. Carbon dioxide capture in metal-organic frameworks. Chem. Rev. 2012, 112, 724-781.

(7) Bazer-Bachi, D.; Assié, L.; Lecocq, V.; Harbuzaru, B.; Falk, V. Towards industrial use of metal-organic framework: Impact of shaping on the MOF properties. Powder Technol. 2014, 255, 52-59.

(8) Seoane, B.; Coronas, J.; Gascon, I.; Benavides, M. E.; Karvan, O.; Caro, J.; Kapteijn, F.; Gascon, J. Metal-organic framework based mixed matrix membranes: A solution for highly efficient $\mathrm{CO}_{2}$ capture? Chem. Soc. Rev. 2015, 44, 2421-2454.

(9) Zhang, Y.; Feng, X.; Yuan, S.; Zhou, J.; Wang, B. Challenges and recent advances in MOF-polymer composite membranes for gas separation. Inorg. Chem. Front. 2016, 3, 896-909.

(10) Hedin, N.; Andersson, L.; Bergström, L.; Yan, J. Adsorbents for the post-combustion capture of $\mathrm{CO}_{2}$ using rapid temperature swing or vacuum swing adsorption. Appl. Energy 2013, 104, 418-433. 
(11) Dechnik, J.; Gascon, J.; Doonan, C. J.; Janiak, C.; Sumby, C. J. New directions for mixed-matrix membranes. Angew. Chem., Int. Ed. 2017, 56, 9292-9310.

(12) Rodenas, T.; Luz, I.; Prieto, G.; Seoane, B.; Miro, H.; Corma, A.; Kapteijn, F.; Llabres i Xamena, F. X.; Gascon, J. Metal-organic framework nanosheets in polymer composite materials for gas separation. Nat. Mater. 2015, 14, 48-55.

(13) Peng, Y.; Li, Y.; Ban, Y.; Jin, H.; Jiao, W.; Liu, X.; Yang, W. Metal-organic framework nanosheets as building blocks for molecular sieving membranes. Science 2014, 346, 1356-1359.

(14) Song, Q.; Nataraj, S. K.; Roussenova, M. V.; Tan, J. C.; Hughes, D. J.; Li, W.; Bourgoin, P.; Alam, M. A.; Cheetham, A. K.; AlMuhtaseb, S. A.; Sivaniah, E. Zeolitic imidazolate framework (ZIF-8) based polymer nanocomposite membranes for gas separation. Energy Environ. Sci. 2012, 5, 8359-8369.

(15) Bachman, J. E.; Long, J. R. Plasticization-resistant $\mathrm{Ni}_{2}$ (dobdc)/ polyimide composite membranes for the removal of $\mathrm{CO}_{2}$ from natural gas. Energy Environ. Sci. 2016, 9, 2031-2036.

(16) Bachman, J. E.; Smith, Z. P.; Li, T.; Xu, T.; Long, J. R. Enhanced ethylene separation and plasticization resistance in polymer membranes incorporating metal-organic framework nanocrystals. Nat. Mater. 2016, 15, 845-849.

(17) Bae, T.-H.; Lee, J. S.; Qiu, W.; Koros, J. W.; Jones, C. W.; Nair, $\mathrm{S}$. A high-performance gas-separation membrane containing submicrometer-sized metal-organic framework crystals. Angew. Chem., Int. Ed. 2010, 49, 9863-9866.

(18) Xiang, L.; Sheng, L.; Wang, C.; Zhang, L.; Pan, Y.; Li, Y. Amino-functionalized ZIF-7 nanocrystals: Improved intrinsic separation ability and interfacial compatibility in mixed-matrix membranes for $\mathrm{CO}_{2} / \mathrm{CH}_{4}$ separation. Adv. Mater. 2017, 29, 1606999.

(19) Phan, A.; Doonan, C. J.; Uribe-Romo, F. J.; Knobler, C. B.; O'Keeffe, M.; Yaghi, O. Y. Synthesis, structure, and carbon dioxide capture properties of zeolitic imidazolate frameworks. Acc. Chem. Res. 2010, 43, 58-67.

(20) Banerjee, R.; Phan, A.; Wang, B.; Knobler, C.; Furukawa, H.; O'Keeffe, M.; Yaghi, O. M. High-throughput synthesis of zeolitic imidazolate frameworks and application to $\mathrm{CO}_{2}$ capture. Science 2008, 319, 939-943.

(21) Yao, J.; Wang, H. Zeolitic imidazolate framework composite membranes and thin films: Synthesis and applications. Chem. Soc. Rev. 2014, 43, 4470-4493.

(22) Schweinefuß, M. E.; Springer, S.; Baburin, I. A.; Hikov, T.; Huber, K.; Leoni, S.; Wiebcke, M. Zeolitic imidazolate framework-71 nanocrystals and a novel SOD-type polymorph: solution mediated phase transformations, phase selection via coordination modulation and a density functional theory derived energy landscape. Dalton Trans. 2014, 43, 3528-3536.

(23) Springer, S.; Baburin, I. A.; Heinemeyer, T.; Schiffmann, J. G.; van Wullen, L.; Leoni, S.; Wiebcke, M. A zeolitic imidazolate framework with conformational variety: Conformational polymorphs versus frameworks with static conformational disorder. CrystEngComm 2016, 18, 2477-2489.

(24) Larson, A. C.; Von Dreele, R. B. General structure analysis system (GSAS). Los Alamos National Laboratory Report LAUR 86748. 2004.

(25) Toby, B. H. EXPGUI, a graphical user interface for GSAS. J. Appl. Crystallogr. 2001, 34, 210-213.

(26) Cerny, R. V.; Favre-Nicolin, V. Direct space methods of structure determination from powder diffraction: Principles, guidelines and perspectives. Z. Kristallogr. 2007, 222, 105-113.

(27) Rogge, S. M. J.; Waroquier, M.; Van Speybroeck, V. Reliably modeling the mechanical stability of rigid and flexible metal-organic frameworks. Acc. Chem. Res. 2018, 51, 138-148.

(28) Rogge, S. M. J.; Vanduyfhuys, L.; Ghysels, A.; Waroquier, M.; Verstraelen, T.; Maurin, G.; Van Speybroeck, V. A Comparison of barostats for the mechanical characterization of metal-organic frameworks. J. Chem. Theory Comput. 2015, 11, 5583-5597.

(29) Sakaida, S.; Otsubo, K.; Sakata, O.; Song, C.; Fujiwara, A.; Takata, M.; Kitagawa, H. Crystalline coordination framework endowed with dynamic gate-opening behaviour by being downsized to a thin film. Nat. Chem. 2016, 8, 377-383.

(30) Hyun, S.-M.; Lee, J. H.; Jung, G. Y.; Kim, Y. K.; Kim, T. K.; Jeoung, S.; Kwak, S. K.; Moon, D.; Moon, H. R. Exploration of gateopening and breathing phenomena in a tailored flexible metal-organic framework. Inorg. Chem. 2016, 55, 1920-1925.

(31) Elsaidi, S. K.; Mohamed, M. H.; Simon, C. M.; Braun, E.; Pham, T.; Forrest, K. A.; Xu, W.; Banerjee, D.; Space, B.; Zaworotko, M. J.; Thallapally, P. K. Effect of ring rotation upon gas adsorption in SIFSIX-3-M $(\mathrm{M}=\mathrm{Fe}, \mathrm{Ni})$ pillared square grid networks. Chem. Sci. 2017, 8, 2373-2380.

(32) Gadipelli, S.; Travis, W.; Zhou, W.; Guo, Z. A thermally derived and optimized structure from ZIF-8 with giant enhancement in $\mathrm{CO}_{2}$ uptake. Energy Environ. Sci. 2014, 7, 2232-2238.

(33) McEwen, J.; Hayman, J.-D.; Ozgur Yazaydin, A. A comparative study of $\mathrm{CO}_{2}, \mathrm{CH}_{4}$ and $\mathrm{N}_{2}$ adsorption in ZIF-8, zeolite-13X and BPL activated carbon. Chem. Phys. 2013, 412, 72-76.

(34) Houndonougbo, Y.; Signer, C.; He, N.; Morris, W.; Furukawa, H.; Ray, K. G.; Olmsted, D. L.; Asta, M.; Laird, B. B.; Yaghi, O. M. A combined experimental-computational investigation of methane adsorption and selectivity in a series of isoreticular zeolitic imidazolate frameworks. J. Phys. Chem. C 2013, 117, 10326-10335.

(35) Ding, L.; Yazaydin, A. O. The effect of $\mathrm{SO}_{2}$ on $\mathrm{CO}_{2}$ capture in zeolitic imidazolate frameworks. Phys. Chem. Chem. Phys. 2013, 15, $11856-11861$.

(36) Morris, W.; Leung, B.; Furukawa, H.; Yaghi, O. K.; He, N.; Hayashi, H.; Houndonougbo, Y.; Asta, M.; Laird, B. B.; Yaghi, O. M. A combined experimental-computational investigation of carbon dioxide capture in a series of isoreticular zeolitic imidazolate frameworks. J. Am. Chem. Soc. 2010, 132, 11006-11008.

(37) Myers, A. L.; Prausnitz, J. M. Thermodynamic of mixed-gas adsorption. AIChE J. 1965, 11, 121-127. 